\title{
O pensar vivenciado na formação de professores
}

\section{Experiential thinking in teacher training ${ }^{1}$}

\author{
Tania Stoltz ${ }^{2}$ \\ Ulrich Weger ${ }^{3}$
}

\begin{abstract}
RESUMO
Analisa-se, neste artigo, um estudo de caso que discute a possibilidade de desenvolvimento do pensar vivenciado na formação de professores. A formação de professores é correntemente conduzida a partir de uma visão reducionista intelectual. Neste estudo, a formação de professores é entendida dentro de uma visão ampliada que inclui o desenvolvimento de forma integrada do querer, sentir e pensar. Ancorados em trabalhos anteriores de Goethe, Schiller e Rudolf Steiner, destacamos a importância e o impacto do trabalho com ciência, atividades criativo-artísticas e desenvolvimento pessoal no processo de formação de professores.
\end{abstract}

Palavras-chave: educação; Steiner; pensar vivenciado.

\begin{abstract}
In this article a case study is analysed which discusses the possibility of development of experiential thinking in teacher training. Teacher training is currently conducted according to an intellectual reductionist view. In this study, teacher training is understood in a broader view that encompasses the integration of will, emotional sensitivity and thinking. Anchored in earlier works by Goethe, Schiller and Steiner, we highlight the importance and the
\end{abstract}

DOI: $10.1590 / 0104-4060.41444$

1 Paper apresentado no 42nd Annual Meeting The Jean Piaget Society: Rethinking Cognitive Development, em Toronto, Canadá.

2 Universidade Federal do Paraná. Setor de Educação. Curitiba, Paraná, Brasil. Rua General Carneiro, $\mathrm{n}^{\circ}$ 460. CEP: 80060-150. O trabalho faz parte das atividades realizadas na Alanus Hochschule, Alemanha, no pós-Doc sênior com bolsa Capes - Coordenação de Aperfeiçoamento de Pessoal de Nível Superior, em 2011-2012, BEX 1056/11-5.

3 Universität Witten/Herdecke, Alemanha. Alfred-Herrhausen-Straße 50, 58448 Witten, $\mathrm{N}-\mathrm{W}$, Deutschland. 
impact of working with science, creative and artistic activities and individual development in the process of teacher training.

Keywords: education; Steiner; experiential thinking.

Imersos na era fáustica de avanços científicos e tecnológicos frenéticos, que em nome do poder e do sucesso sacrifica relações, assim como descaracteriza a Natureza, observa-se, cada vez mais, a incapacidade de deter o processo, de parar e de refletir sobre os rumos tomados pela própria existência.

Somente o presente é a nossa infelicidade, motivo pelo qual nós, contemporâneos modernos no espírito de Fausto, não podemos nos deter nem por um instante sequer e temos de marchar para o ainda-não-existente como que sobre o chão em brasas, sempre acossados pelos ritmos inexoráveis de uma dinâmica onipresente, sempre insatisfeitos, em permanente inquietação, em meio a uma caçada infindável pela riqueza e felicidade presumivelmente sempre maiores, que jamais se oferecem no presente, pois se evadindo sem cessar para o futuro. (JAEGER, 2007, p. 320).

A educação não tem se dado conta deste estado de coisas. Por um lado, tende a reificar a ciência obtida a partir de uma racionalidade vazia que não se compromete com o outro. Por outro lado, busca de forma extremada o sensível e muitas vezes nele se perde por não se dar conta da sua incapacidade na luta contra o trágico. Arte, intuição, sensibilidade, imaginação, criatividade aparecem como apelos evidentes em um tempo ainda regido sobremaneira pela racionalidade intelectual. Gauthier (1999); Plaza (2003); Almeida (2006); Palma (2006); Reis, Guerra e Braga (2006); Kestler (2006); Massarini, Moreira e Almeida (2006); Sanchez Rodrigues (2007); Laurenti (2008); Nóbrega (2008); Veiga (2008); Schieren (2008, 2010); Benchetrit (2009); Ferreira (2010); Stoltz e Weger (2012); Veiga e Stoltz (2014) exemplificam apenas alguns estudos cujo objeto volta-se a uma resposta para além da obtida por intermédio dessa ciência.

Conhecer requer vivência, envolvimento! Se a razão levou a tantas conquistas e (ir)reparáveis deslizes, buscam-se outros canais para acessar o conhecimento por meio do diálogo sensível, emocional, intuitivo e racional. (GAUTHIER, 1999). Sabe-se que o conhecimento altera o conhecedor e que o fenômeno é constituído pelo objeto utilizado para medi-lo. (BOHR, 1995). Neste caso, se a educação se prende a um discurso abstrato e este é a medida das avaliações, é justamente este que vai nortear a vida dos que a ele se sujeitam. Este estudo 
se propõe a percorrer outro caminho. Busca-se identificar a possibilidade de desenvolvimento do pensar vivenciado na educação. Fundamenta-se em Steiner (1996, 1998, 2000, 2003, 2004a, 2004b); Goethe (2000a e b); Günther (1981) e Schiller (1990). Justifica-se na necessidade de desenvolvimento de um novo olhar à educação que tenha como meta a integração entre o querer, o sentir e o pensar na construção de um individualismo ético. Parte-se do pressuposto de que o pensar vivenciado requer a necessária superação de uma abordagem comportamental para uma investigação da vivência em si e, neste sentido, os resultados podem até ser comunicados, mas perdem o seu sentido se não forem compreendidos a partir do indivíduo. (WELBURN, 2005; WEGER, 2007, 2008; VEIGA, 2008, 2010).

Como exemplo emblemático deste pensar vivenciado tem-se o cientista e poeta Goethe. Goethe responde ao furacão da modernidade, tão bem caracterizado em seu Fausto, por meio de uma fenomenologia crítica que aponta para a Arte. À "disposição para a inquietude, a obsessão impulsiva por agitação, a embriaguez de velocidade como marca característica da existência tipicamente moderna de Fausto" (JAEGER, 2007, p. 320), Goethe propõe "o deter-se em face do Belo, o qual Fausto amaldiçoa em sua angústia mórbida". (JAEGER, 2007, p. 318). É neste sentido que Seel (2007) refere-se à importância do sentido estético.

Com o atrofiamento do sentido estético se perderia uma receptividade e sensibilidade pessoais e coletivas para tudo o que no presente histórico do aqui e agora está em meio a toda mediação histórica e biográfica, social e coletiva, e que é capaz de mover e comover imediatamente provocando a fantasia e a reflexão. (SEEL, 2007, p. 130, tradução nossa).

Contudo,

[...] o seu sentido primordial está em si mesmo; em um encontrar-se a si mesmo que se efetua como um encontrar o mundo, e que não vai mais além deste mesmo encontro. Neste encontro os seres humanos contam com uma de suas melhores possibilidades de deixar-se ser no tempo de seu existir. (SEEL, 2007, p. 130, tradução nossa).

Para Goethe (2000a e b), o conhecimento apresenta sempre o envolvimento do conhecedor e diz respeito à nossa relação com o mundo, ao nosso 
papel na continuação do mundo. Neste sentido, Goethe observa a necessidade de análise de qualquer aspecto a partir de diferentes perspectivas. O papel da interpretação no conhecimento une a ciência à arte, destacando a criação em ambas. Iniciando pela indiferenciação entre pessoa e mundo, o desenvolvimento humano requer a separação da natureza pelo pensar, para depois reencontrá-la em um pensar intuitivo.

A Natureza, assim como a Arte, pode ser contemplada, sentida, vivida, não propriamente conhecida. A Arte permite uma intuição do infinito. Este infinito representa o que é mais elevado, a Unidade e origem de todas as coisas. A empatia com este infinito, com o que é sublime, é possibilitada pela intuição na Arte que influencia o coração e o sentido. Guidotti (2011) observa que o sublime em Goethe tem aproximações com a ideia kantiana; no entanto, para Goethe o Belo passa para o conceito de sublime, diferentemente de Kant. Para Goethe, o sujeito é finito, mas sua busca é infinita. Para Guidotti (2011), Goethe se aproxima da ideia kantiana do sublime.

Como o belo, o sublime também compartilha estas características: apraz por si próprio; pressupõe um juízo de reflexão; a contemplação é desinteressada; é singular e universalmente válida; reivindica o sentimento de prazer, mas não o conhecimento do objeto. (GUIDOTTI, 2011, p. 127).

Steiner (2004a) procurou justificar o tipo de ciência que Goethe tinha proposto intuitivamente. A arte do pensamento, para Steiner, é a resposta estética do homem para o mundo por meio do conhecimento. Ela é o complemento necessário que nos resgata da redução ao vazio e ao nada. Representa a resposta humana para o entendimento do mundo e para transformá-lo. Por trás da ciência e da arte há uma unidade, acessível pela intuição. Neste processo, segundo Veiga (2008), não há a desconsideração de um conhecimento racional, mas a sua necessária interpretação individual.

Intuição não é aqui compreendida como algo irracional. Ela é muito mais o pensar consciente do espírito, que se experiencia a si próprio como criador e aos conteúdos ideais colocados em atividade como autônomos. A autonomia ideal que se experimenta em uma articulação interna autônoma é o conteúdo da intuição e, ao mesmo tempo, também o sentido da racionalidade, oculto na consciência empírica ordinária. O pensamento em direção à progressiva intuitividade permite à racionalidade recuperar a dimensão mítica perdida. 
[...] A racionalidade possibilita assim uma vivência da autonomia, que se assenta na diferenciação do sujeito de outros objetos que o rodeiam. Assim, o homem passa a estar em frente a um mundo de objetos como contemplador. No pensamento intuitivo, por outro lado, inicia-se a autoconsciência no processo produtivo de se relacionar com as formas ideais das coisas. A consciência racional da diferenciação torna-se então uma consciência intuitiva interpretativa. (VEIGA, 2008, p. 27, tradução nossa).

A Pedagogia Waldorf tenta estimular o trabalho conjunto entre arte e pensamento científico no sentido do desenvolvimento da consciência. O conhecimento passa a ser entendido como a atualização de nossa profunda relação com a origem da realidade do mundo e requer a ação. Neste sentido, o pensamento não nos fragmenta, mas nos liga a uma ordem do mundo que está de acordo com a ordem própria por meio da integração do pensar com o corpo e com os sentimentos. (STEINER, 2000). Este é movimento no individualismo ético. Nos emancipamos não pela submissão a uma ordem externa, mas por meio da valorização do outro e de nosso desejo de aprendizado e de mudança. É por esta razão que o pensar vivenciado representa a possibilidade de nos transcendermos. A discussão de Schiller (1990) é especialmente relevante aqui, pois apresenta a proposta de uma educação estética do homem a partir da integração entre o impulso forma e o impulso matéria.

Para Acosta López (2008, p. 11), Schiller propõe "uma sensibilidade sensível à razão ou a ideia de uma liberdade estética, que se traduz em um acordo da razão e da sensibilidade pelo prazer livre e desinteressado". O gosto é condição necessária da liberdade e favorece a virtude. Com sua crítica a Kant, Schiller observa assim a possibilidade da superação estética do dever. (BARBOSA, 2005; ACOSTA LÓPEZ, 2007, 2008; RIVERA DE ROSALES, 2008). Utilizando-se do aporte teórico de Schiller, Acosta López (2007) e Scheck (2009) pontuam a necessidade de recuperação do trágico em sua relação com o sublime. Os fenômenos absolutamente grandes, ameaçadores, poderosos permitem perceber a incapacidade e a inadequação da sensibilidade. O sentimento do sublime nos eleva por sobre nossas próprias limitações. O sublime, que possibilita a contemplação da Unidade, exige a postura de expectador, não de protagonista. $\mathrm{O}$ "sublime termina por erigir-se em uma ponte estética que une o sensível e a moral, o natural e o espiritual, a dor e o prazer no próprio sujeito. O sentido do sublime está na possibilidade de reunificar o sujeito dividido pela própria modernidade." (SCHECK, 2009, p. 81, tradução nossa).

Em Schiller (1990), a beleza, a verdade e a bondade seriam o resultado do impulso lúdico que representa a síntese entre o divino e o animal a partir 
de um querer humano. Exige assim uma racionalidade não só teórica, mas prática e estética. A concretização deste objetivo na educação está relacionada à construção de um novo olhar. Olhar que se volte não só à intelectualidade e que vemos como relacionado ao desenvolvimento de um pensar vivenciado. $\mathrm{O}$ desenvolvimento do pensar vivenciado requer uma educação que integre as três dimensões com as quais o homem se relaciona com a sua natureza: corpo, alma e espírito. Requer, assim, uma educação que siga o desenvolvimento humano.

\section{Método}

Optou-se pelo método de estudo de caso por possibilitar a discussão aprofundada de aspectos observados em seu contexto de origem. Foi analisado o caso de uma professora participante de Seminário avançado envolvendo a perspectiva de Rudolf Steiner de liberdade e sua relação com a educação. Dos quinze participantes do Seminário, somente dois disponibilizaram o material produzido para pesquisa, visto configurar-se como material que envolve aspectos da vida pessoal de cada participante. Destes dois, tomou-se o que desenvolveu maior número de trabalhos artísticos. Este Seminário foi ofertado em um Curso de Pós-Graduação em Educação, envolvendo mestrandos e doutorandos. Em seu início, foi conduzido por um professor de uma universidade alemã e, na continuidade, pela pesquisadora.

Os participantes desenvolveram, durante 45 horas presenciais, distribuídas em três horas por semana e durante um semestre, atividades de leitura e discussão de textos da obra Filosofia da Liberdade, de Rudolf Steiner. A metodologia de trabalho desses textos orientou-se por perguntas que suscitaram a reflexão crítica sobre aspectos essenciais da obra de Steiner. Com a evolução dos encontros, os participantes passaram a desenvolver atividades criativo-artísticas relacionadas ao tema e à sua vida. Essas atividades foram desenvolvidas em outro espaço, que não na universidade. Foram oportunizados vários momentos de interação entre os participantes a partir das atividades criativo-artísticas nos encontros do Seminário. Essas atividades foram assim desencadeadas: os participantes foram convidados a representar criativamente, em material de livre escolha, algo que fosse realmente importante e significativo em suas vidas. Na sequência foram convidados a refletir sobre as seguintes perguntas: 1 . Existe alguma relação da criação com a sua vida? 2. Qual o significado de cada elemento contido na criação e da relação entre eles? 3. Como você se sente após a atividade? 4. Você se lembrou, durante a atividade, de passagens ou de fatos de sua vida? 5. Como 
você avalia a importância do processo criativo para a sua vida? Os participantes eram convidados a partilhar com o grupo a sua criação, bem como as respostas às perguntas. Semanalmente, a cada dia de encontro no Seminário avançado, eram socializados os trabalhos criativos trazidos pelos participantes, suas reflexões em relação a questões sobre a própria existência, bem como discutidos capítulos da obra Filosofia da Liberdade.

Foi analisada a trajetória individual da participante em estudo, buscando evidenciar regularidades e mudanças a partir da evolução dos encontros e tendo por base as observações da coordenadora do Seminário e do grupo, as realizações criativas e o registro das falas da participante na socialização de seus trabalhos criativos ao grande grupo. A discussão foi baseada em Steiner, Schiller e Goethe e buscou trazer indícios do pensar vivenciado na trajetória da participante analisada.

\section{Resultados e discussão}

Miriam está cursando mestrado em educação. É pedagoga em uma ONG que trabalha com crianças e adolescentes em situação de vulnerabilidade social. Tem 36 anos e, embora tenha um relacionamento estável, não é casada e não tem filhos. Mora com os pais. A primeira criação artística de Miriam retrata uma mulher-menina obesa, de cabeça para baixo e em formato de um ponto de interrogação. É um desenho feito com lápis preto e ocupa todo o espaço da folha.

Esta criação retrata o presente momento que estou vivenciando em meu desenvolvimento como ser. A tentativa de me retratar em forma de um ponto de interrogação simboliza as minhas dúvidas existenciais. É como me vejo hoje: sem identidade, deformada, "boiando", sem chão, sem apoio. (Miriam).

De uma maneira muito criativa, Miriam retrata a perplexidade no confronto consigo mesma. O deixar-se levar no vazio. $\mathrm{O}$ enfrentamento e a coragem de se enxergar em sua relação com o mundo. Sem o saber, Miriam incorpora o drama do niilismo moderno. É interessante lembrar aqui que o caminho de Steiner levou-o a entrar em contato com Nietzsche, no entanto, não compartilha da reação de pânico implícita ao pensamento nietzschiano. (WELBURN, 2005). Para 


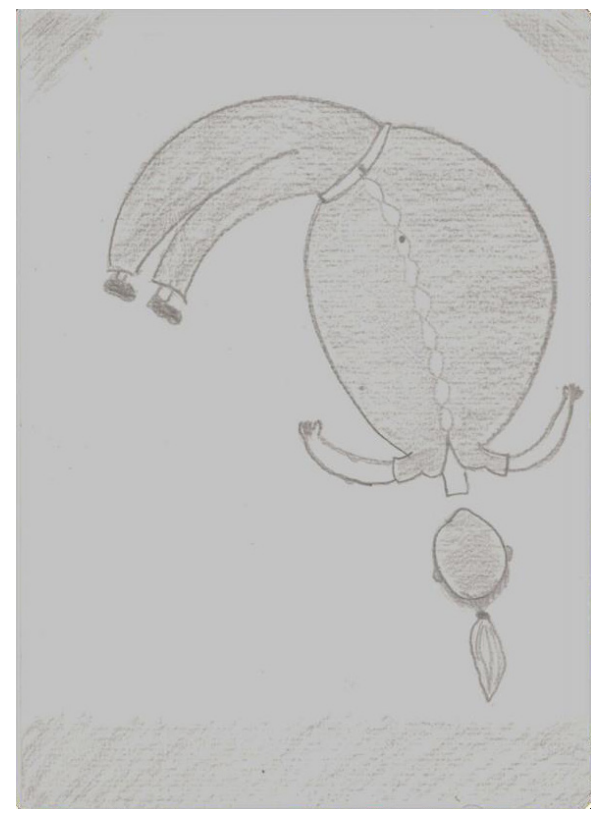

FONTE: Desenho da participante Miriam.

Nietzsche, se o pensamento humano não tem base nas verdades metafisicamente necessárias, então não pode haver certo ou errado, nem verdade absoluta; haverá somente o nada. Steiner também enfrenta o nada e o entende como uma condição com a qual temos de nos relacionar. Steiner (2000) responde que o conhecimento não precisa e nem tem fundamentos. O pensamento estabelece conexões entre as coisas, cujas validades não precisam ser dadas por bases metafísicas nem por qualquer outra entidade hipotética, como a coisa em si. Contra o niilismo nietzschiano, Steiner indica a certeza espiritual do conhecimento. Contra a ideia do Super-homem, forte o bastante para enfrentar o nada em si mesmo, Steiner nos fala do ideal do "espírito livre" encontrando novas situações com novas ideias morais. Poderíamos pensar que, tal qual Steiner e Nietzsche, a libertação dos códigos repressivos de moralidade ou de fundamentos externos ao que o homem pode encontrar com o desenvolvimento de seu pensamento configura-se como primeira necessidade no desenvolvimento de um pensar vivenciado.

Nesse processo e ainda na apresentação da sua primeira obra criativo-artística no Seminário, Miriam diz sentir-se "envergonhada e sem criatividade", após a atividade. Pode-se entender esse sentimento na constatação da falta de apoio, de base em sua vida, buscando-a em algo externo. A ausência de criati- 
vidade expressa por Miriam indica-nos exatamente a necessidade de busca da própria verdade, de desenvolvimento da individualidade e a possibilidade de ter sido conduzida basicamente por outros em seu processo de vida. Miriam observa muitas relações da criação com a sua vida, "principalmente relacionadas à adolescência. Não sei 'o que' eu era nem se eu gosto do que eu era, ou achava que era, sei lá". Quanto à atividade criativa, diz "sempre me considerei criativa na elaboração de histórias, textos, músicas, mas hoje tenho dúvidas se eu realmente era criativa ou não. Hoje me sinto desprovida de criatividade". A relação espontânea que faz entre a criação, a qual retrata seu momento atual, e a sua adolescência apontam nesta direção. É como se continuasse com o desenvolvimento do pensamento do início da adolescência.

A segunda produção criativa de Miriam foi uma coruja imensa e sisuda, que ocupa a totalidade da folha e foi feita com lápis preto, sem cores. Quanto ao seu significado, expressa: "Meus gostos variam conforme fases: fase do marrom, do azul, das listras, das flores, do Pateta, das bruxas... durante a fase das bruxas, passei a gostar de corujas". Ao ser perguntada sobre o ar severo das sobrancelhas da coruja, expressa: "Não sou brava", ao que a coordenadora pergunta se é ela que está retratada na sua criação. Ela indica que sim e fala de sua "relação individual com a noite, sabedoria, noite, desejo de voar..." É importante destacar que, embora as atividades criativas fossem realizadas em outro espaço, que não na Universidade, bem como as questões, as respostas eram sempre ampliadas com as socializações no grupo e, principalmente, com as perguntas feitas pelo grupo sobre o significado de elementos contidos na obra do indivíduo. Esta situação já foi observada em estudos anteriores (STOLTZ, 2010), onde se pôde verificar que o autor da produção criativo-artística traz muitos elementos inconscientes na sua obra que, com as perguntas sobre o porquê de sua presença, contribuíram significativamente para a ampliação da consciência a partir da reflexão.

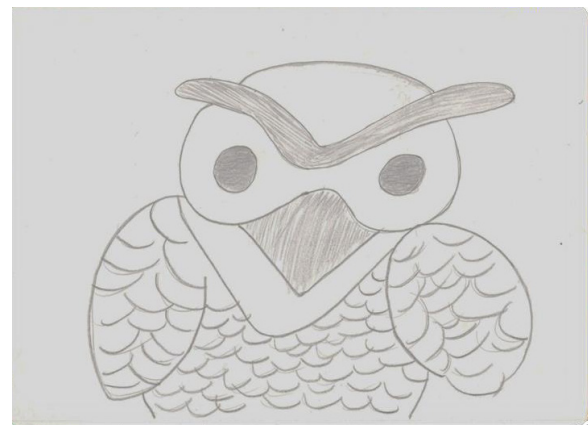

FONTE: Desenho da participante Miriam. 
Miriam sentiu-se frustrada porque não conseguiu reproduzir a imagem que estava em sua mente e disse que se lembrou principalmente de seu pai que a chamava de "corujinha" e de uma senhora coordenadora geral da ONG onde trabalha que relacionou esse fato com o de ela gostar de corujas. Durante a sessão ficou evidente para ela que tentou se retratar como coruja e a importância que dá à relação com seu pai, sugerindo que tenta seguir o que este espera dela. Expressa que para ela é importante retomar a "autoconfiança” em sua capacidade criativa. Ao ser perguntada sobre as grandes asas da coruja e destas estarem coladas ao corpo, expressa: "é meu desejo de alçar voo e meu sentimento de amarrar". Sem o saber, Miriam expõe o dilema entre lançar-se à aventura do desenvolvimento de uma individualidade e, ao mesmo tempo, querer prender-se às bases de um caminho já acabado e indicado externamente. Miriam diz, ainda, que a obra não estava completa e que ela gostaria de reforçar os traços a lápis, o que fez no mesmo dia. A sua corporificação em forma de coruja da ideia que o pai faz dela é, consciente ou inconscientemente, reforçada por essa atitude, seja porque esta lhe dá segurança, seja porque materializa um estado de ser necessário de ser refletido. No movimento de Miriam em torno do desenvolvimento de um pensar vivenciado, observa-se a necessidade e a coragem de identificação das bases sobre as quais o pensamento está fundado, se externas ou internas.

É com a terceira criação de Miriam que aparecem pela primeira vez cores. São cores frias: vários tons de verde e azul e uma mancha vermelha. Quanto ao significado da sua obra, Miriam observa:

Muitas direções. Inicio timidamente cada "empreitada" e depois vou me aprofundando nas coisas. Tentei usar o mesmo número de vezes todos os tons verdes contidos na caixa de lápis de cor. Onde está vermelho, a princípio iria deixar em branco, mas achei muito sem graça e escolhi uma cor forte para dar um "tchan"! (Miriam).

"Senti-me muito bem ao fazer e ao terminar, mesmo quando meu namorado criticou o que havia feito. Enquanto fazia a atividade, procurei deixar a mente livre. Não pensei em nada, além das cores e da direção da pintura”. (Miriam). É surpreendente notar no movimento de Miriam a retomada da possibilidade de muitas direções, já presentes quando fala da coruja retratada anteriormente. O seu uso das cores sugere não só a experiência com muitas direções, mas a presença do querer, no uso da cor vermelha em determinado ponto da obra, dando indicativos da busca de um caminho próprio integrando o querer, o sentir e o pensar. Nesta terceira criação e com relação ao processo criativo em sua vida, 
diz: "um caminho para retomar, conhecer a minha própria identidade". Esta fala pôde ser reforçada quando expressa que seu namorado não gostou do que ela fez, mas "mesmo assim" ela se sentiu bem durante o trabalho.

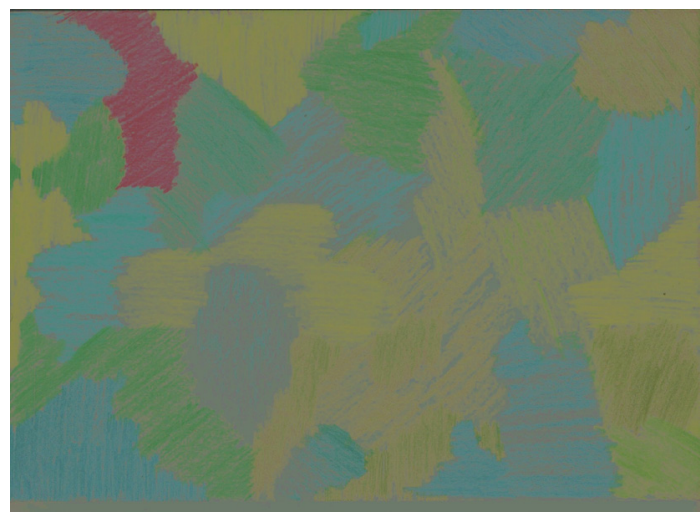

FONTE: Desenho da participante Miriam.

As cores aparecem novamente na quarta atividade criativo-artística. Miriam apresenta uma composição com cotonetes, organizada de forma vibrante.

A ideia surgiu durante um banho, enquanto enxugava a cabeça. Por ter o hábito de usar "cotonetes" todos os dias. Como sabia que estava sem cotonetes há dias, senti certa angústia e cheguei a ter uma visão com um monte de cotonetes enfileirados. Decidi retratar. Representam a minha crise de abstinência. O fundo laranja serve para destacar o branco do algodão. Senti-me bem por ter conseguido terminar, pois foi muito cansativo fazer o fundo e pintar os cotonetes. No final fiquei satisfeita, mesmo não tendo ficado exatamente como imaginei. (Miriam).

Quanto à possível relação com a sua vida, expressa: "Pensei muito no momento de escolhas e opções que estou passando."

O processo criativo na vida é entendido "como um processo de reencontro comigo mesma e de libertação". Concluiu, após a exposição no grupo, que passou a ouvir mais as pessoas. É digna de atenção a angústia narrada pela falta de cotonetes e relacionada à criação de Miriam. Pode estar relacionada à necessidade de estar atenta ao que o mundo lhe apresenta. Steiner (2000) expressa os componentes essenciais do processo cognitivo como a observação e o pensar, e depois o pensar sobre o pensar no desenvolvimento do individualismo ético. 


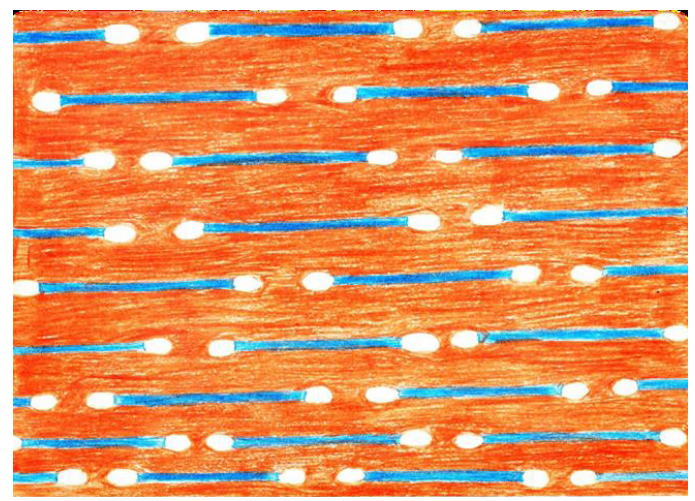

FONTE: Desenho da participante Miriam.

A quinta atividade realizada envolve outra composição com cores, agora com grande variedade. A composição ocupa toda a folha. "Tentei expressar como me sinto ao final desse semestre: bem e confiante. As cores e o entrelace representam a diversidade encantadora e a cumplicidade do grupo que participou desse Seminário". (Miriam).

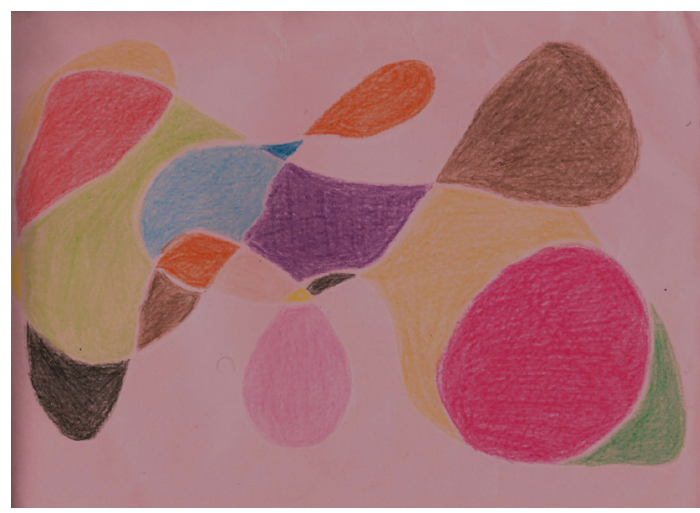

FONTE: Desenho da participante Miriam.

Miriam sentiu-se "confiante e agradecida pela oportunidade de revelar, ouvir, dividir... tantas experiências de vida". Sobre a relação com a sua vida observa: "pensei em como me sentia no início do ano e como me sinto hoje. Vejo-me mais amadurecida e preparada". Em relação ao processo criativo, 
observa: “Como não gosto muito de me 'encarar' no espelho, vejo a produção artística como forma de me retratar, expressar meus sentimentos e emoções, não apenas para os outros, mas para que eu mesma possa me "enxergar'”. Esta atividade traz elementos essenciais que indicam uma busca de sua verdade em sintonia com uma visão integrada de mundo. Mais ainda, trazem à tona a necessidade da expressão criativo-artística, mesmo para os que não têm a sua vida pautada pela criatividade e pela arte. Por outro lado, aponta para a importância do desenvolvimento do pensar em relação à própria existência, em busca de seu sentido e da sua verdade. O percurso de Miriam, semelhante e diferente ao dos outros participantes do Seminário, sugere a necessidade do trabalho articulado entre ciência, atividade criativo-artística e a própria vida no desenvolvimento do pensar vivenciado. (STEINER, 2004a). Miriam nos provoca com a ideia da necessidade de criar para se entender, se enxergar, se sentir. Especial atenção é dada por Miriam ao grupo nesse processo. Cada um dos participantes contribuiu com o desenvolvimento do outro, desencadeando um sentimento de pertencimento, de cumplicidade, que se estendeu para fora da Universidade e que persiste até hoje. O Seminário descrito marcou a vida não só dos participantes, mas da própria coordenadora que, embora acreditasse na possibilidade dessa nova experiência, foi surpreendida pelo seu alcance não só em termos de reflexão sobre a própria vida, mas do conteúdo do pensamento de Steiner e sua validade a partir das discussões da obra Filosofia da Liberdade.

\section{Considerações finais}

O desenvolvimento do Eu é trabalho para o resto da vida. Quando a educação se preocupa em seguir o desenvolvimento humano, em respeitar as necessidades deste desenvolvimento em uma perspectiva evolutiva, há a possibilidade da vivência do bem, do belo e da verdade, pois esses não são o resultado do seguimento de um caminho externo, mas do desenvolvimento de uma interioridade intencionada que concorda com a essência percebida no mundo. É por essa razão que o caminho da conquista desta individualidade ética, expressão do conceito de liberdade em Steiner e objeto das reflexões científicas durante o Seminário, passa por fazer as pazes com o mundo, passa pela resposta à pergunta fundamental sobre a minha relação com o mundo. Envolve, assim, conhecimento e ação prática em uma perspectiva que diz respeito ao sujeito integral em seu querer, sentir e pensar. A educação formal, da forma como se encaminha em sua principal vertente materialista, está muito distante da conquista deste ideal. 
A partir do estudo observa-se que a possibilidade de desenvolvimento do pensar vivenciado na formação de professores está vinculada à articulação da ciência à realidade a partir de atividades criativo-artísticas, seguindo Goethe e Steiner. Tal possibilidade se concretiza na vivência individual, o que constitui um dilema para uma ciência que rejeita a possibilidade de uma investigação válida e com sentido do indivíduo. (WEGER, 2008). A importância do pensar vivenciado, sobretudo para aqueles que se ocupam da formação de pessoas, está no desenvolvimento de uma individualidade racional sensível, justamente pela possibilidade de se experimentar por meio da arte e da atividade criativa a bondade, a verdade e a beleza. Neste sentido, inspirando-se em Nielsen e Haralambous (2011), observa-se a necessidade de articulação das atividades imaginativo-criativas ao contexto e a propósitos significativos visando uma participação consciente. A imaginação criativa, por si, não leva a um desenvolvimento integrado. Como articular significativamente conhecimento, autoconhecimento e ação prática transformadora na educação? Eis a tarefa da educação do futuro.

\section{REFERÊNCIAS}

ACOSTA LOPEZ, M. R. Tragedia como libertad y teodicea: acerca de una relación entre Schiller y Hegel. Estud. filos, Medellín, n. 36, Ago. 2007. Disponível em: <http://www. scielo.org.co/scielo.php?script=sci_arttext\&pid=S012136282007000200010\&lng=en\& nrm=iso $>$. Acesso em: 25 out. 2012.

ACOSTA LOPEZ, M. R. ¿Una superación estética del deber?: La crítica de Schiller a Kant. Episteme, Caracas, v. 28, n. 2, Dic. 2008. Disponível em: <http://www.scielo.org. ve/scielo.php?script=sci_arttext\&pid=S079843242008000200003\&lng=es\&nrm=iso $>$. Acesso em: 25 out. 2012.

ALMEIDA, C. Fayga Ostrower, uma vida aberta à sensibilidade e ao intelecto. Hist. cienc. saúde - Manguinhos, Rio de Janeiro, 2006. Disponível em: <http://www.scielo. br/scielo.php?script=sci_arttext\&pid=S010459702006000500017\&lng=en\&nrm=iso $>$. Acesso em: 25 out. 2012 .

BARBOSA, R. A especificidade do estético e a razão prática em Schiller. Kriterion, Belo Horizonte, v. 46, n. 112, dez. 2005. Disponível em: <http://www.scielo.br/scielo. php? script=sci_arttext\&pid=S0100512X2005000200008\&lng=en\&nrm=iso $>$. Acesso em: 25 out. 2012.

BENCHETRIT, H. Aproximaciones a la verdad en el arte. Argos, Caracas, v. 26, n. 50, Jun. 2009. Disponível em: <http://www.scielo.org.ve/scielo.php?script=sci_arttext\&pi $\mathrm{d}=\mathrm{S} 025416372009000100003 \& \operatorname{lng}=\mathrm{es} \& \mathrm{nrm}=\mathrm{iso}>$. Acesso em: 25 out. 2012. 
BOHR, N. Física atômica e conhecimento humano. Rio de Janeiro: Contraponto, 1995.

FERREIRA, F. R. Ciência e arte: investigações sobre identidades, diferenças e diálogos. Educ. Pesqui., São Paulo, v. 36, n. 1, abr. 2010. Disponível em: <http:/www.scielo.br/ scielo.php?script $=$ sci_arttext\&pid $=\mathrm{S} 151797022010000100005 \& \operatorname{lng}=\mathrm{en} \& \mathrm{nrm}=\mathrm{iso}>$. Acesso em: 25 out. 2012.

GAUTHIER, J. O que é pesquisar - entre Deleuze-Guattari e o candomblé, pensando mito, ciência, arte e culturas de resistência. Educ. Soc., Campinas, v. 20, n. 69, dez. 1999. Disponível em: $<$ http://www.scielo.br/scielo.php?script=sci_arttext\&pid=S0101$-73301999000400002 \& \operatorname{lng}=\mathrm{en} \& n r m=$ iso $>$. Acesso em: 25 out. 2012.

GOETHE, J. W. von. Schriften zur Kunst. München: Deutscher Taschenbuch Verlag GmbH \& Co. KG, 2000a. v. 12, n. 12.

GOETHE, J. W. von. Naturwissenschaftliche Schriften I. München: Deutscher Taschenbuch Verlag GmbH \& Co. KG, 2000b. v. 13, n. 02.

GUIDOTTI, M. Imbricações entre Goethe e Kant: Arte, Natureza e Sublime. Pandaemonium ger. (On-line), São Paulo, n. 17, 2011. Disponível em: <http://www.scielo. br/scielo.php?script $=$ sci_arttext\&pid $=\mathrm{S} 198288372011000100008 \& \operatorname{lng}=\mathrm{pt} \& \mathrm{nrm}=\mathrm{iso}>$. Acesso em: 25 out. 2012.

GÜNTHER, H. Goethe anschauendes Denken. Frankfurt am Main: Insel Verlag, 1981.

JAEGER, M. A aposta de Fausto e o processo da Modernidade: figurações da sociedade e da metrópole contemporâneas na tragédia de Goethe. Estud. av., São Paulo, v. 21, n. 59, abr. 2007. Disponível em: <http://www.scielo.br/scielo.php?script=sci arttext\&pid $=\mathrm{S} 010340142007000100025 \& \operatorname{lng}=$ en $\&$ nrm=iso $>$. Acesso em: 25 out. 2012.

KESTLER, I. M. F. Johann Wolfgang von Goethe: arte e natureza, poesia e ciência. Hist. cienc. saúde - Manguinhos, Rio de Janeiro, 2006. Disponível em: <http://www.scielo. br/scielo.php?script $=$ sci_arttext\&pid $=$ S0104-59702006000500003\&lng $=$ en\&nrm=iso $>$. Acesso em: 25 out. 2012 .

LAURENTI, C. Bergsonismo, psicologia e liberdade. Psicol. estud., Maringá, v. 13, n. 1, mar. 2008. Disponível em: <http:/www.scielo.br/scielo.php?script=sci arttext\&pid=S1413-73722008000100006\&lng=en\&nrm=iso $>$. Acesso em: 25 out. 2012.

MASSARANI, L.; MOREIRA, I. de C.; ALMEIDA, C. Para que um diálogo entre ciência e arte?. Hist. cienc. saúde - Manguinhos, Rio de Janeiro, 2006. Disponível em: <http:// www.scielo.br/scielo.php?script=sci_arttext\&pid=S0104-59702006000500001\&lng=e n\&nrm=iso $>$. Acesso em: 25 out. 2012.

NOBREGA, T. P. Corpo, percepção e conhecimento em Merleau-Ponty. Estud. psicol. (Natal), Natal, v. 13, n. 2, ago. 2008. Disponível em: <http://www.scielo.br/scielo. php?script $=$ sci_arttext\&pid=S1413294X2008000200006\&lng=en\&nrm $=$ iso $>$. Acesso em: 25 out. 2012. 
NIELSEN, T. W.; HARALAMBOUS, B. Imagination as evolution - an educational and human development perspective. ROSE, v. 2, n. 1, p. 24-33, 2011. Disponível em: $<$ http://www.rosejourn.com/index.php/rose/article/view/60/88>. Acesso em: 25 out. 2012.

PALMA, C. Arte e ciência no palco. Hist. cienc. saúde-Manguinhos, Rio de Janeiro, 2006. Disponível em: $<$ http://www.scielo.br/scielo.php?script=sci_arttext\&pid=S0104$-59702006000500014 \& \operatorname{lng}=$ pt\&nrm=iso $>$. Acesso em: 25 out. 2012.

PLAZA, J. Arte/ciência: uma consciência. ARS (São Paulo), São Paulo, v. 1, n. 1, 2003. Disponível em: $<$ http://www.scielo.br/scielo.php?script=sci_arttext\&pid=S1678$-53202003000100004 \& \operatorname{lng}=\mathrm{en} \& n r m=$ iso $>$. Acesso em: 25 out. 2012.

REIS, J. C.; GUERRA, A.; BRAGA, M. Ciência e arte: relações improváveis?. Hist. cienc. saúde - Manguinhos, Rio de Janeiro, 2012. Disponível em: $<$ http://www.scielo. br/scielo.php?script $=$ sci_arttext\&pid=S010459702006000500005\&lng=en\&nrm=iso $>$. Acesso em: 25 out. 2012 .

RIVERA DE ROSALES, J. Schiller: la necesidad transcendental de la belleza. Estud. filos, Medellín, n. 37, Feb. 2008. Disponível em: <http://www.scielo.org.co/scielo. php?script $=$ sci_arttext\&pid=S0121-36282008000100011\&lng=en\&nrm=iso $>$. Acesso em: 25 out. 2012 .

SANCHEZ RODRIGUEZ, M. A. La ciencia como poética de la inteligencia. educ. educ., Chia, v. 10, n. 2, Dic. 2007. Disponível em: <http://www.scielo.org.co/scielo. php? script $=$ sci_arttext\&pid $=$ S0123-12942007000200009\&lng=es\&nrm=iso $>$. Acesso em: 25 out. 2012 .

SCHECK, D. O. Lo sublime en la modernidad: De la retórica a la ética. Rev. latinoam. filos., Ciudad Autónoma de Buenos Aires, v. 35, n. 1, Mayo 2009. Disponível em: $<$ http:// www.scielo.org.ar/scielo.php?script=sci_arttext\&pid=S1852-73532009000100002\&lng $=$ es\&nrm=iso $>$. Acesso em: 25 out. $201 \overline{2}$.

SCHILLER, F. A educação estética do homem. São Paulo: Iluminuras, 1990.

SCHIEREN, J. Die Veranlagung von intuitiven Fähigkeiten in der Pädagogik. Research on Steiner Education (RoSE), Norway and Germany, Rudolf Steiner University College; Alanus University of Arts and Social Sciences, v. 1, n. 1, p. 07-18, Jan. 2010. Disponível em: <http://www.rosejourn.com/index.php/rose/article/viewFile/3/48>. Acesso em: 25 out. 2012.

SCHIEREN, J. (Hrsg.). Rationalität und Intuition in philosophischer und pädagogischer Perspektive. Frankfurt am Main: Peter Lang, 2008.

SEEL, M. Un paso al interior de la estética. Traducción de: Sebastián Pereira Restrepo. Estud. filos, Medellín, n. 36, Ago. 2007. Disponível em: <http://www.scielo.org.co/ scielo.php?script $=$ sci_arttext\&pid $=$ S012136282007000200007\&lng=es\&nrm $=$ iso $>$. Acesso em: 25 out. 2012.

STEINER, R. A arte na educação - II. São Paulo: Antroposófica, 2003. 
STEINER, R. A educação da criança: segundo a ciência espiritual. 3. ed. São Paulo: Antroposófica, 1996.

STEINER, R. A filosofia da liberdade: fundamentos para uma filosofia moderna. Resultados com base na ciência pensante, segundo o método das ciências naturais. São Paulo: Antroposófica, 2000.

STEINER, R. Arte e estética segundo Goethe: Goethe como inaugurador de uma estética nova. Tradução de: Marcelo da Veiga. São Paulo: Antroposófica, 1998.

STEINER, R. O método cognitivo de Goethe: linhas básicas para uma gnosiologia da cosmovisão goethiana. 2. ed. São Paulo: Antroposófica, 2004a.

STEINER, R. Teosofia: introdução ao conhecimento supra-sensível do mundo e do destino humano. 7. ed. São Paulo: Antroposófica, 2004b.

STOLTZ, T. A constante criação de si mesmo a partir do outro. In: GUÉRIOS, E.; STOLTZ, T. (Orgs.). Educação e alteridade. São Carlos: EdUFSCar, 2010. p. 167-178.

STOLTZ, T.; WEGER, U. Piaget and Steiner: science and art in the process of formation. Research on Steiner Education (RoSE), Norway and Germany, Rudolf Steiner University College; Alanus University of Arts and Social Sciences, v. 3, n. 1, p. 134-145, July 2012. Disponível em: <http://www.rosejourn.com/index.php/rose/article/viewFile/106/131>. Acesso em: 25 out. 2012.

VEIGA, M. Cada homem é um problema! Considerações sobre a compreensão do outro no enfoque científico de Goethe. In: GUÉRIOS, E.; STOLTZ, T. (Orgs.). Educação e Alteridade. São Carlos: EdUFSCar, 2010. p. 25-38.

VEIGA, M. Realität und intuition. In: SCHIEREN, J. (Hrsg.). Rationalität und Intuition in philosophischer und pädagogischer Perspektive. Frankfurt am Main: Peter Lang, 2008. p. 13-31.

VEIGA, M.; STOLTZ, T. (Orgs.). O pensamento de Rudolf Steiner no debate científico. Campinas, SP: Editora Alínea, 2014.

WEGER, U. Die Frage nach der Natur des Bewusstseins. Rudolf Steiners Beitrag zu den Grundlagen der Psychologie. In: Die Drei, Mai 2008.

WEGER, U. Grenzen einer Philosophie des Fleishes. Intentionalität als Grundlage psychologischer Forschung. In: Die Drei, Juli 2007.

WELBURN, A. A filosofia de Rudolf Steiner e a crise do pensamento contemporâneo. São Paulo: Madras, 2005.

Texto recebido em 19 de maio de 2015. Texto aprovado em 10 de junho de 2015. 
